\title{
O processo de renovação das áreas centrais na cidade contemporânea: $O$ caso do conjunto arquitetônico e paisagístico da Praça do Congresso, em Criciúma (SC)
}

\author{
The renewal process of central areas in the contemporary city: The case of the \\ 'Praça do Congresso' architectural and landscape complex in Criciúma
}

Gustavo Rogério De Lucca ${ }^{[0]}$, Margareth de Castro Afeche Pimenta[a,b]

[a] Universidade Federal de Santa Catarina (UFSC), Programa de Pós-Graduação em Urbanismo, História e Arquitetura da Cidade, Florianópolis, SC, Brasil

[b] Universidade Federal de Santa Catarina (UFSC), Programa de Pós-Graduação em Geografia, Florianópolis, SC, Brasil

\section{Resumo}

A expansão urbana desordenada no Brasil e a consolidação da cidade corporativa têm estimulado, com a conivência do Estado neoliberal, a propagação de modos de ocupação cada vez mais vinculados a interesses imobiliários imediatos. A ausência de planejamento urbano de caráter social é percebida principalmente nos médios e grandes centros urbanos, onde se registra um agressivo processo de renovação das áreas centrais, cada vez mais ousado, alterando inclusive, irreversivelmente, a paisagem de núcleos históricos. É o caso de setores da centralidade urbana de Criciúma/SC, cidade produzida sob influências econômicas da mineração de carvão e, posteriormente, por outras atividades industriais. É destaque o conjunto arquitetônico e paisagístico da Praça do Congresso, objeto de estudo deste artigo, formado a partir das primeiras décadas do século XX com residências em estilos variados, desde chalés com influências no Romantismo europeu a exemplares da arquitetura modernista. Juntas com a praça, configuravam um espaço de referência em qualidade de vida e importante para a preservação de vínculos identitários e de memória. Considera-se, no entanto, que as transformações mais recentes são parte de um quadro nacional de empobrecimento da urbanização e demonstram que a subserviência das políticas públicas a interesses econômicos imediatos tendem a desaparecer, em breve, com parte importante da diversidade dos conjuntos históricos brasileiros.

Palavras-chave: Capital imobiliário. Paisagens históricas. Políticas públicas. Centralidade. Criciúma.

\section{Abstract}

The unplanned urban expansion in Brazil and the consolidation of corporate city have encouraged, with the connivance of the neoliberal State, the propagation of occupation models increasingly tied to immediate real estate interests. The lack of social character urban planning is perceived mainly in medium and large cities, where an aggressive renovation process of the central areas is registered, even altering the landscape of historic centers irreversibly. This is the case of Criciúma, Santa Catarina state, a municipality developed under

GRL é arquiteto e urbanista; mestrando em Urbanismo, História e Arquitetura da Cidade, e-mail: arqgustavodelucca@gmail.com MCAP é arquiteta e urbanista; doutora em Géographie de l’Aménagement et d'Urbanisme, e-mail: afeche@arq.ufsc.br 
the economic influences of coal mining and, subsequently, of other industrial activities. The highlight is the architectural and landscape complex of the 'Praça do Congresso', the object of study of this article, formed since the early decades of the $20^{\text {th }}$ century with houses in various styles, from cottages with influences from European Romanticism, to copies of modern domestic architecture. Together with the square, they configure a reference space in quality of life, important to the preservation of memory and identity ties. The most recent changes are part of a national context of impoverishment of urbanization, and they demonstrate that the subservience of public policies to immediate economic interests tend to mischaracterize, in the near future, important part of the diversity of Brazilian historical complexes.

Keywords: Estate capital. Historic landscapes. Public policies. Urban centrality. Criciúma.

\section{Introdução}

Algumas vezes cidades diferentes sucedem-se no mesmo solo e com o mesmo nome, nascem e morrem sem se conhecer, incomunicáveis entre si. (Calvino, 1990, p. 30)

Como construção coletiva e permanente, a cidade é a materialização de relações econômicas, das ações políticas e dos valores sociais que, a todo o momento, configuram a paisagem. Fotografias em preto e branco de outros tempos são prova do quanto os desenhos que compunham o espaço urbano acompanhavam os valores e as dinâmicas de sua geração. Na concepção lefebvriana, "[...] a estrutura social está presente na cidade, é aí que ela se torna sensível, é aí que significa uma ordem. Inversamente, a cidade é um pedaço do conjunto social [...]" (Lefebvre, 2001, p. 66). A paisagem que permanece diante das transformações da sociedade é, portanto, cenário de memórias, coletivas ou individuais, e da identidade que ainda vive, uma vez que possibilita à vida cotidiana o contato permanente com as lembranças e registros dos diferentes períodos do processo de produção da cidade.

Se, por um lado, se reconhece a importância da paisagem como vínculo da cidade contemporânea com sua história e identidade, por outro, registra-se que o Brasil tem colecionado perdas irreversíveis em conjuntos urbanos de relevância patrimonial. De norte a sul do país, nas grandes e médias cidades, monumentos, conjuntos arquitetônicos e espaços públicos que sobreviveram à efervescência econômica da segunda metade do século XX têm sido completamente substituídos em razão dos interesses imobiliários mais recentes. Essas poderosas pressões, cada vez mais ousadas, têm revelado uma explícita subserviência do poder público ao capital imobiliário, que se apoderou da responsabilidade de desenhar a cidade. Condicionadas ao capital, ao mesmo tempo em que há estímulo ao espraiamento da malha urbana, as áreas centrais têm se expandido a partir da densificação do solo e de processos de verticalização cada vez mais agressivos às suas paisagens.

Embora tenha raízes na configuração da cidade corporativa (Santos, 2009), o processo de renovação das áreas centrais tem se intensificado a partir destes primeiros anos do século XXI e põe em xeque a permanência de importantes conjuntos históricos brasileiros. E apesar dos questionamentos fundamentados pela evolução dos conceitos e das técnicas de proteção patrimonial, a propaganda com discursos sedutores e a resultante da ausência de critérios de interesse público/social sobre as legislações urbanísticas têm registrado na paisagem o amesquinhamento na produção da cidade e o enfraquecimento de quaisquer valores que não sejam o econômico.

Através da análise do processo de transformação do conjunto arquitetônico e paisagístico da Praça do Congresso, localizado no centro de Criciúma/SC, este artigo visa alertar para a necessidade de ações efetivas para a preservação do remanescente patrimonial fragmentado pelas substituições mais recentes e, sob uma interpretação do contexto político atual, contribuir para o debate acerca das perspectivas para a cidade brasileira num quadro de desenvolvimento prioritariamente consumista. A Praça do Congresso e tantos outros casos pelo Brasil denunciam a emergência de uma agenda para as cidades que faça jus a sua condição de obra histórica e diversa, que transpassa os interesses imediatos do presente e que permita a evocação da memória e do pertencimento. 


\section{Questão de contexto: a cidade corporativa e a fragmentação das paisagens históricas}

De substituições de pequenos acervos históricos a casos de renovação de grandes espaços contíguos a centros urbanos, são cada vez mais notáveis os avanços do capital imobiliário sobre áreas de interesse coletivo. A desfiguração do texto original do Plano Diretor e o caso da construção de um hotel na Ponta do Coral, em Florianópolis/SC; a ameaça de demolição do cais José Estelita, importante remanescente da arquitetura portuária no Recife/PE; ou as intenções de demolição de edificações oitocentistas no interior catarinense têm em comum as relações corporativistas que impõem às cidades um processo de expansão conduzido pelas dinâmicas de acumulação de capital. Embora estejam atrelados a características territoriais locais, são ramificações que fazem parte de um quadro internacional de urbanização, o qual se torna mais agressivo e poderoso quando as políticas públicas nacionais ou locais são negligentes ao interesse coletivo.

Para entender o momento atual, é importante primeiramente considerar o processo de monopolização do capital, no qual Braverman (1977) atribui ao Estado o papel condicionante e estimulador para uma dinâmica distributiva cada vez mais desigual em favor de grupos políticos ou econômicos. Acrescenta mais: que "[...] o poder do Estado tem sido utilizado em toda parte pelos governos para locupletar a classe capitalista, e por grupos ou indivíduos para locupletar-se si mesmos [...]" (Braverman, 1977, p. 242). Milton Santos (2009), por sua vez, considera o capital monopolista um fator determinante sobre a organização do território e de seu processo de urbanização, o que estimula o corporativismo na organização das cidades. No Brasil, esse processo tomou formas junto ao desenvolvimento de uma rede industrial e de comunicação territorial a partir dos anos 1950 e se intensificou sob o regime político autoritário das décadas seguintes.

A formação oligárquica da sociedade brasileira, somada ao capitalismo monopolista, estruturou as cidades com base em segmentações compostas por grupos, lobbies e organizações que, em aliança ou em conflito mútuo, usam estratégias e táticas para a prevalência de seus interesses setoriais sobre o espaço urbano. Essa lógica, além de fragilizar e cultura republicana, atribui à estrutura pública uma viciosa relação de subordinação a empresas e grupos com maior poder econômico. Com o advento do neoliberalismo, as relações corporativistas se tornaram ainda mais explícitas, em um movimento dialético à retração das políticas públicas urbanas. E somado às dinâmicas da pós-modernidade, as cidades têm sido induzidas a generalizações cada vez mais intensas de padrões arquitetônicos e a modos de ocupação constituídos por uma infinidade de fragmentações e contradições.

A dinâmica imobiliária é evolutiva, difunde-se pelo sistema financeiro e molda na paisagem urbana a negligência e as relações corporativistas que a amparam. Conjuntos arquitetônicos se fragmentam e monumentos históricos importantes se apequenam frente à escala dos novos investimentos, à infração de normas de proteção patrimonial, à elaboração de planos diretores de péssima qualidade técnica e à ineficácia dos órgãos de proteção. Não há limites claros nem resultados consolidados. Supõe-se por enquanto que, sob a lógica da "destruição criativa" (Harvey, 2007), está iminente um completo processo de renovação das paisagens históricas, especialmente nos centros urbanos.

Como exemplo claro tem-se a fragmentação da Praça do Congresso e seu entorno, que configuravam até a virada para o século XXI um conjunto completo e representativo dos principais períodos econômicos de Criciúma. As transformações mais recentes não só registram a produção da cidade pelo setor imobiliário, mas também a submissão do desenho urbano às fragilidades e subserviências do setor público local.

\section{Formação e evolução do conjunto arquitetônico e paisagístico da Praça do Congresso}

Localizada no sul de Santa Catarina, Criciúma tem sua origem associada ao quadro imigratório da segunda metade do século XIX, o qual tratou de estimular a ocupação do território catarinense, especialmente nos inóspitos vales entre o planalto serrano e o litoral. Por aproximadamente três décadas, entre 1880 e meados de 1910, a cidade foi se desenvolvendo através do comércio de excedentes agrícolas e sob todas as dificuldades da precária rede urbana que caracterizava as áreas coloniais do sul do estado.

A matriz econômica local se alterou apenas quando se mostraram favoráveis as possibilidades de extração comercial das jazidas de carvão mineral que haviam sido descobertas em seu território. Sob o contexto geopolítico das duas guerras mundiais, registrou-se a constituição de uma estrutura logística e legislativa que estimulou a formação de uma poderosa indústria 
extrativista, que, por sua vez, passou a conduzir as dinâmicas econômicas e políticas da cidade. Em poucos anos, Criciúma tornara-se a maior produtora de carvão no Brasil, combustível essencial para o abastecimento do parque industrial que se formava na região Sudeste. As riquezas, os contrastes sociais e o crescente movimento migratório de operários que buscavam trabalho nas minas de carvão foram formando signos, identidades e configurando o espaço urbano.

Influenciado pelo fluxo populacional atraído pela mineração, o núcleo colonial que caracterizava o centro da cidade de economia agropastoril foi se expandindo por meio do adensamento e do espraiamento da malha viária. E nesse processo, modos de ocupação distintos foram caracterizando a urbanização. Durante os anos 1940, sob a efervescência econômica estimulada pela Segunda Guerra Mundial, as diversas frentes de expansão da centralidade consolidavam a formação de setores de predominância comercial e de novas áreas residenciais, estas últimas que já surgiam marcadas com o explícito agrupamento de classes sociais.

Foi nesse quadro que se configurou o espraiamento da malha viária no sentido nordeste do núcleo histórico, área adjacente à Praça Nereu Ramos, logradouro central da cidade. Razão determinante para essa frente de expansão foi a construção, a partir de 1942, da sede regional do Departamento Nacional de Produção Mineral (DNPM), uma autarquia federal constituída em 1934 para fiscalizar e regulamentar a produção mineral do país, que estava submetida a um processo de aparelhamento estatal. Segundo Balthazar (2001), a estrutura física do DNPM no centro de Criciúma se constituía pelo prédio do escritório e mais oito residências para abrigar seus empregados, que, juntas, contribuíram para estimular a urbanização em seu entorno.

O prédio principal do DNPM se destacava na paisagem central pela imponência produzida por sua escala, pelos afastamentos que o diferenciavam das demais edificações da rua e pela rígida simetria arquitetônica de suas arcadas e acessos. Tornou-se um dos símbolos do poder e da solidez da economia carbonífera. Foi construído sobre um aclive na rua Cel. Pedro Benedet, a meio caminho entre a Praça Nereu Ramos e o Hospital São José, este último que marcava o limite do perímetro urbano central ${ }^{1}$. As

\footnotetext{
1 A rua Cel. Pedro Benedet tem sua origem na configuração de uma rede de caminhos entre os núcleos coloniais italianos do sul catarinense. Trata-se do trecho inicial da antiga Estrada
}

casas, por sua vez, foram instaladas aos fundos do prédio principal em sequência linear, mas soltas no lote, com varandas voltadas para o espaço público da rua. A planta segmentada, os telhados aparentes e a discrição do decoro, quase ausente nas fachadas, anunciavam uma fase de transição de estilos arquitetônicos, em um sutil afastamento do art déco para o moderno.

Concomitante à configuração do conjunto arquitetônico, também foi estímulo para a expansão urbana da centralidade a formação de uma segunda praça pública, localizada a cerca de 200 metros da praça central, defronte às casas do DNPM. Registra-se, para este caso, que o fator que induziu à consolidação do espaço público foi a realização, em dezembro de 1946, de um dos eventos mais importantes da história de Criciúma: o Congresso Eucarístico. Mais do que um espetáculo religioso, o Congresso marcou o 33a aniversário da instalação da indústria carbonífera e o reconhecimento de Criciúma como a "Capital do Carvão" (Nascimento, 2012). Para dar apoio ao evento, de repercussão nacional, uma área próxima da praça central foi reservada para estacionamento e missas campais: era a Praça do Congresso, que fora urbanizada de fato apenas nos anos 1960.

A Praça do Congresso se compôs ao conjunto arquitetônico do DNPM, o que contribuiu para desenvolver uma área de expansão com predominância residencial. Gradativamente, ainda na década de 1940, novos exemplares da arquitetura doméstica foram ocupando o perímetro da praça e iniciando a urbanização das ruas mais próximas. Tratava-se, pelos tipos arquitetônicos, da configuração de uma zona residencial para as famílias mais abastadas da cidade, inclusive aquelas enriquecidas pelo capital proveniente da mineração.

O conjunto que se formava era uma composição de vários estilos, desde chalés de influência tardia do Romantismo europeu a residências inspiradas nas diretrizes do Modernismo, o qual se difundia pelo país como movimento arquitetônico de vanguarda. Destacava-se a Residência Balsini, construída no fim dos anos 1940 pelo médico José Tarquinio Balsini, na confluência das ruas Barão do Rio Branco e Lauro Müller. Foi um dos primeiros exemplares do Modernismo na cidade e tornou-se referência arquitetônica pelas grandes aberturas em vidro, pelo pilotis composto

Geral Cresciuma-Urussanga, adjacente à Praça Nereu Ramos, e que foi urbanizado já nas primeiras décadas do século XX. 
por pilares em "V" e pela implantação diagonal que a valorizava na esquina da praça. Somada às outras casas, rompeu com o modo de ocupação tradicional da edificação sem afastamentos e constituiu um conjunto urbano e paisagístico com características contemporâneas ao seu tempo.

Nos anos 1950 e 1960, acompanhando a efervescência econômica proporcionada pelos recordes de produção do carvão mineral de Criciúma para fins energéticos e siderúrgicos, o espaço urbano central se transformava e se adaptava às demandas de uma população cada vez maior e diversificada. Adensavam-se e inseriam-se novas atividades às áreas comerciais mais próximas da Praça Nereu Ramos e se expandiam as áreas residenciais, a exemplo do entorno da Praça do Congresso (Figura 1). Condicionada pela valorização imobiliária, exemplares da arquitetura moderna de alto padrão foram gradativamente cercando a praça e se espalhando pelos arruamentos do entorno. Tratava-se de uma parcela mínima da população, como proprietários de companhias mineradoras, de indústrias cerâmicas, políticos e profissionais bem remunerados com formação superior, que podiam pagar pela boa localização e por projetos arquitetônicos com tecnologias construtivas de vanguarda.

0 criciumense Fernando Carneiro, o primeiro arquiteto de Santa Catarina, é responsável pelo projeto de uma série de residências construídas nas proximidades da Praça do Congresso, tanto no período antecedente quanto posterior à sua urbanização. Entre elas, a Residência Balsini, de 1965, que se destacava pelos balanços no telhado e pelas esquadrias venezianas em guilhotina, elemento principal de suas fachadas. Também naquele entorno fora construída em 1972 a residência Manique Barreto, propriedade de um dos ex-prefeitos de Criciúma, que tirou proveito do concreto armado para criar elementos curvos, pouco comuns nas casas modernas.

No ano de 1967, por encomenda da Prefeitura, o logradouro correspondente à Praça do Congresso foi, enfim, urbanizado. Segundo Carneiro (2012), autor do projeto, uma de suas diretrizes foi aproveitar algumas nascentes que havia no terreno para a construção de um lago. Analisando o desenho da Praça, percebe-se certa influência da escola moderna através da nítida separação de usos por uma malha de caminhos hierarquizados que definiram e conectaram os setores de lazer infantil e esportivo, o lago e uma ampla área gramada arborizada.

As passagens para pedestres foram projetadas ortogonalmente e diferem dos caminhos circulares da Praça Nereu Ramos. A palmeira imperial e o ipê-amarelo, árvores símbolos nacionais, foram priorizadas. Esta praça recebeu a placa comemorativa

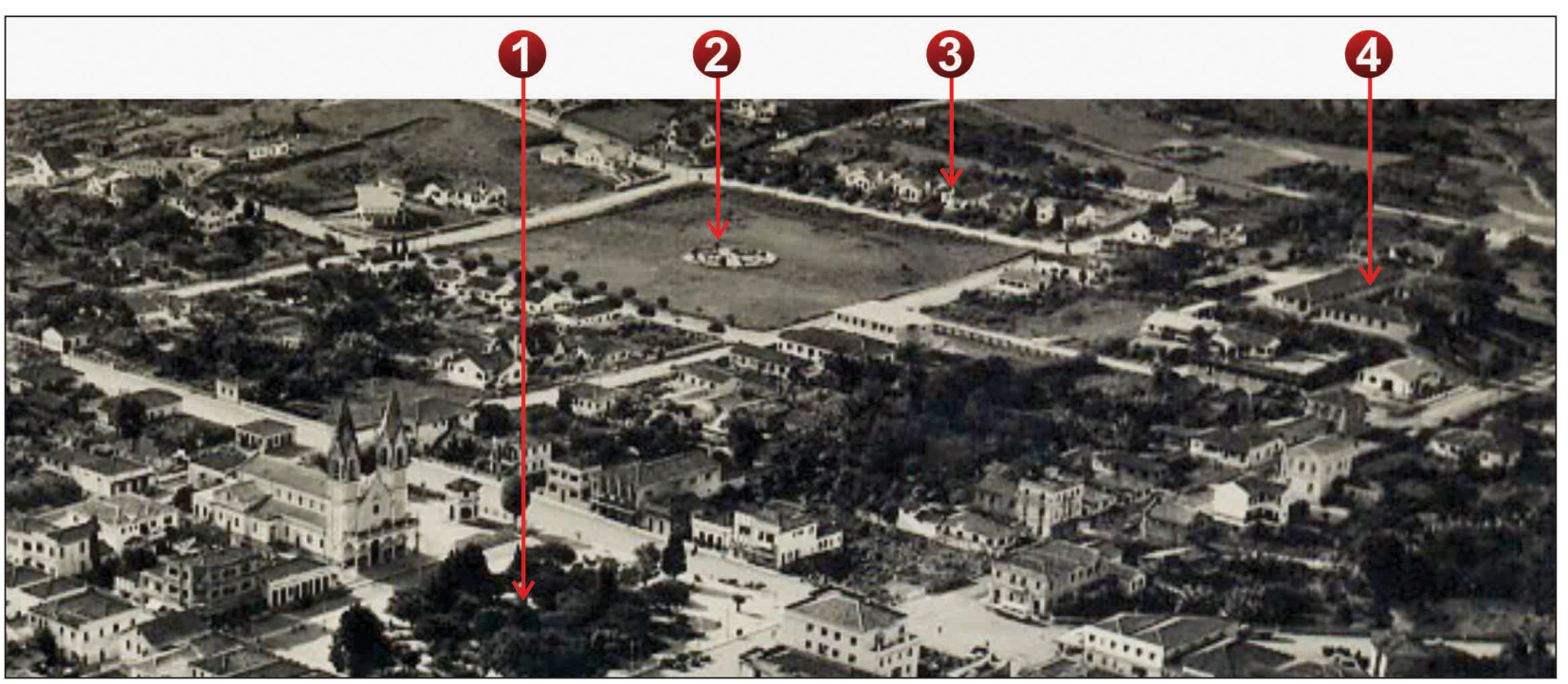

Figura 1 - Praça do Congresso e sua inserção na cidade em 1951 Fonte: Elaborado pelo autor com base em Skyscrapercity (2011). Nota: (1) Praça Nereu Ramos / (2) Praça do Congresso / (3) Conjunto de casas do DNPM / (4) Escritório do DNPM. 
do Congresso Eucarístico ali realizado e ainda os bustos do Engenheiro Aníbal Bastos e do prefeito Addo Caldas Faraco (Carneiro, 2012, p. 250).

A consolidação da praça e sua integração com as edificações mais próximas trataram de estabelecer um conjunto que se tornou referência de qualidade de vida na cidade. Através de fotografias datadas das décadas de 1960 e 1970 é possível perceber a configuração de uma diversificada composição de estilos e tipologias arquitetônicas (Figura 2). O conjunto do DNPM, os chalés com inspirações europeias e as residências modernistas representavam na arquitetura e na paisagem a transição da "capital do carvão" para a cidade moderna que Criciúma almejava ser.

\section{Os primeiros edifícios no entorno da Praça do Congresso}

0 processo de industrialização no Brasil exerceu forte pressão demográfica sobre as cidades, especialmente nos anos 1960 e 1970 (Santos, 2009). Legitimada pela ideologia do crescimento, pela urbanização acelerada e pela difusão de tecnologias construtivas, registrou-se um claro movimento de renovação em centralidades urbanas de todo o país, inclusive nas cidades de médio porte. Acompanhando as dinâmicas nacionais, foi nessa fase que a matriz econômica de Criciúma passou por um inédito processo de diversificação. As frequentes crises no setor carbonífero, que oscilava contrário à cotação do petróleo, o estágio de acumulação de
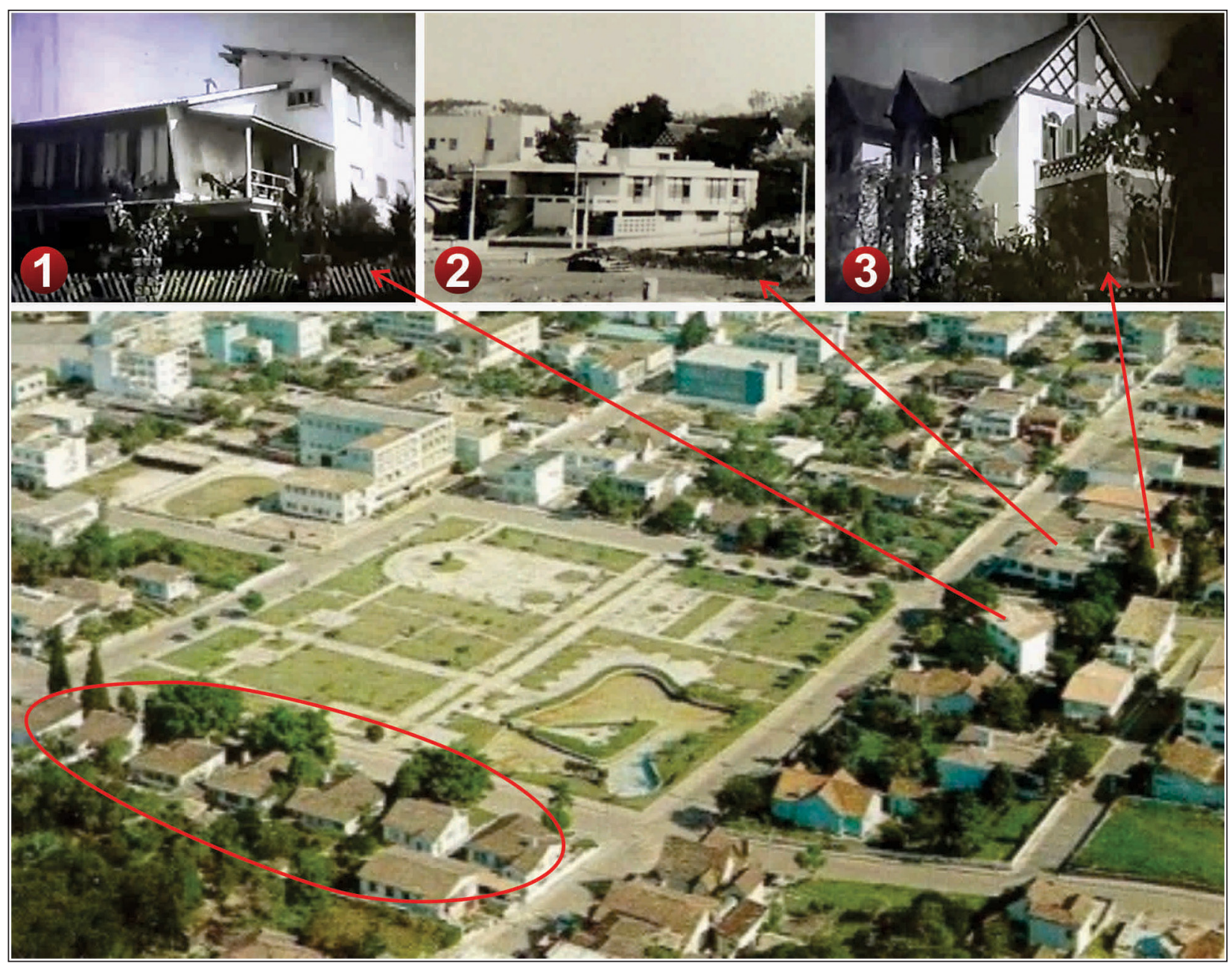

Figura 2 - Praça do Congresso e entorno no início da década de 1970

Fonte: Elaborado pelo autor com base em Gericke (1960) [Captura de tela] e Zappelini (1970).

Nota: Casa 1 - Residência Balsini (anos 1940) / 2 - Residência Balsini (1965) / 3 - Chalé da década de 1940. Abaixo, destaque para algumas casas do DNPM 
capital pela elite mineradora em contradição à forte organização sindical dos mineiros, a poluição por todos os lados e o comprometimento da imagem da cidade foram fatores determinantes para que o carvão compartilhasse espaço com outros segmentos industriais, tais como a cerâmica de revestimentos, a indústria química, de polímeros e de confecção.

A efervescência econômica da cidade foi repercutindo no entorno da Praça do Congresso através dos primeiros traços de um processo de renovação das residências unifamiliares. É o caso do Edifício Dr. Jorge, que substituiu duas casas defronte à Praça, no cruzamento das ruas Barão do Rio Branco com a Lauro Müller, em 1972 (Figura 3). Há de se reconhecer, no entanto, que o novo edifício não comprometeu a percepção do conjunto nem a qualidade do espaço urbano. Foi concebido com cinco pavimentos, sem muros ou grades, e com sacadas em concreto contornando as fachadas que têm contato direto com as ruas. A escala moderada e os detalhes construtivos o inseriram harmonicamente ao conjunto paisagístico, que nos anos 1970 se caracterizava pela predominância da arquitetura moderna.

A industrialização, a atmosfera progressista e a busca pela construção da imagem de uma cidade moderna, limpa e dinâmica conduziu a produção urbana da Criciúma dos anos 1970. Ao mesmo tempo, a organização de uma classe de agentes imobiliários passou a exercer maior influência sobre as políticas públicas de urbanização, o que foi caracterizando, do ponto de vista do capital imobiliário, a formação da cidade corporativa. Sob esse contexto, a municipalidade passou a regulamentar o uso e ocupação do solo, primeiramente com a aprovação do Plano Diretor de 1973, o primeiro a ser implementado em Criciúma², que estimulou o adensamento ao propor uma Zona de Densidade Alta $^{3}$ em toda a área central, inclusive no entorno da Praça do Congresso, e, posteriormente, através Plano de 1984, que previu alturas de 8 e 12 pavimentos naquele mesmo perímetro (Criciúma, 1984).

\footnotetext{
${ }^{2}$ O primeiro Plano Diretor de Criciúma é datado de 1957, mas, na prática, não foi aplicado.

3 A ZDA (Zona de Densidade Alta) do Plano Diretor de 73 não delimitava o gabarito, pois definia os limites construtivos apenas através do Índice de Aproveitamento, que variava entre 3 e 5 , com restrições de recuo distintas para cada índice (Criciúma, 1973).
}

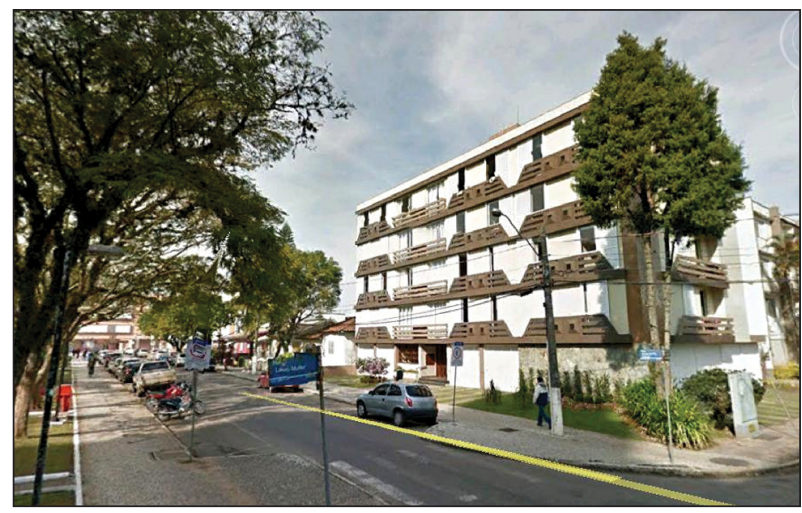

Figura 3 - Edifício Dr. Jorge, de 1972.

Fonte: Google Street View (201 la).

Nota: Projeto do arq. Fernando Carneiro.

Apesar da permissividade das legislações, a maior parte do acervo arquitetônico da Praça do Congresso foi sobrevivendo às dinâmicas econômicas e se manteve preservado até os últimos anos do século XX, ainda que desde os anos 1980 já tenham sido introduzidos os primeiros edifícios com dez pavimentos, mas sem alterar a percepção do conjunto de valor patrimonial. Enfatiza-se, nesse caso, que a acumulação de capital nas mãos de alguns industriais locais se revelava pela construção de residenciais em ruas adjacentes à Praça, projetados com exclusividade para as famílias mais abastadas da cidade. Foi o caso do Residencial De Lucca, localizado na rua Santo Antônio (onde o zoneamento de 1984 permitia 12 pavimentos), construído por proprietários da indústria cerâmica de mesmo nome.

Mesmo com a construção de edifícios com mais de dez pavimentos, a materialização da acumulação de capitais na paisagem da década de 1980 foi apenas o prelúdio do processo de renovação urbana assistido dos anos 1990 em diante. Considera-se, para este caso, que o Plano Diretor de 1984 passou a ser instrumento regulamentador da fragmentação do conjunto arquitetônico, num momento em que os setores produtivos locais entram em crise e a cidade se insere num novo ciclo econômico.

\section{O processo de fragmentação do conjunto}

À luz dos arranjos geopolíticos e da dinâmica de acumulação de capital em países desenvolvidos nos anos 1970, o Brasil caminhava para um quadro neoliberal de desregulamentação de setores produtivos 
e de recuo de políticas públicas de urbanização. Nesse contexto, a partir da metade da década de 1980, indo contra a tantas manifestações da riqueza industrial, o processo de desregulamentação da mineração do carvão brasileiro até sua total liquidação no ano de 1990 provocou o surgimento de novas dinâmicas de ocupação no centro de Criciúma.

A estagnação na economia repercutiu numa escassez de empregos sem precedentes na cidade. Sem perspectivas em curto prazo e na busca de novas oportunidades de trabalho, muitos dos que foram afetados pela crise emigraram para os EUA e Europa no decorrer da década de 1990. Em 1999, segundo publicação da revista Veja (Buchalla \& Verano, 1999), já se estimavam aproximadamente 25 mil criciumenses morando nos EUA, especialmente na cidade de Boston/MA, o que representava, conforme Costa (2010), cerca de 8\% da população de brasileiros residindo naquele país. Muitos deles mantiveram vínculos com a terra natal por meio da compra de apartamentos em Criciúma, o que fez aquecer, em meio à estagnação das atividades extrativistas e industriais, o mercado imobiliário local.

Ainda sob a vigência do Plano Diretor de 1984, imagens do fim da década de 1990 registram a centralidade urbana sendo configurada por um padrão de ocupação verticalizado e sem nenhum critério de planejamento paisagístico. As tipologias cada vez mais homogeneizadas deixavam clara a fragilidade da legislação como peça técnica e a ausência de quaisquer medidas efetivas para a preservação de bens de valor patrimonial, ainda que desde 1985 o município tivesse regulamentado uma lei de tombamentos - Lei no 2.063 (Monteiro, 2013). Por outro lado, apesar da dinâmica imobiliária, o acervo de residências unifamiliares no perímetro da Praça do Congresso pouco se alterava, talvez pela sua condição de área mais valorizada da cidade, que não foi absorvida pelo capital moderado da classe média, em parte mantida pela remessa dos emigrantes.

A construção civil amenizou a crise econômica da década 1990 ao gerar impostos, movimentar capital e absorver parte da mão de obra desempregada na cidade. Por outro lado, consolidou suas influências sobre o espaço urbano e sobre as políticas públicas. A aprovação do Plano Diretor de 1999 demonstrou a pretensão de explorar as possibilidades econômicas imobiliárias ao aumentar o potencial construtivo por todo o centro da cidade. No entorno da Praça do
Congresso, o novo zoneamento passou a permitir até 16 pavimentos contáveis (o que exclui subsolo, garagens e 1/3 do ático), praticamente o dobro das alturas permitidas pelo Plano de 84 .

Diante dos índices construtivos permissíveis e do momento econômico favorável, o capital imobiliário passou a exercer pressões consideráveis sobre todo o centro urbano, inclusive nos lotes mais valorizados. Não demorou, nesse contexto, para se suceder no entorno da Praça do Congresso um verdadeiro bota-abaixo nas edificações residenciais datadas de ciclos econômicos precedentes. Contradizendo os conceitos contemporâneos de preservação patrimonial vinculada à paisagem, o conjunto que sobrevivera às transformações tipológicas dos anos 1970, 80 e 90 estava, enfim, ameaçado pela lógica imobiliária imediatista do século XXI.

\section{A Praça do Congresso na urbanização contemporânea}

Ao estimular a verticalização e a homogeneização dos padrões construtivos para todo o centro da cidade, negligenciando prováveis consequências permanentes sobre localizações com fortes vínculos históricos, a legislação de 1999 regulamentou no espaço uma visão imediatista de cidade. Tornou-se um instrumento de submissão da produção coletiva a interesses setoriais, especialmente pelo não reconhecimento, de modo efetivo, de direitos não associados a valores econômicos.

Combinado à falta de ações concretas para a preservação do acervo de valor patrimonial, o Plano de 1999 tornou mais rentáveis as possibilidades de investimentos imobiliários no entorno da Praça do Congresso. A essas condições favoráveis também se acrescenta a gradativa recuperação econômica da cidade nos anos 2000, a acumulação de capitais por intermédio de uma diversificação cada vez maior das atividades produtivas e o retorno de parte da população emigrada aos EUA na década anterior. Em síntese, um incremento da margem de lucro do incorporador através do potencial construtivo e do momento econômico favorável para a formação de novos consumidores.

Como resultante da dinâmica urbana local, a maior parte dos imóveis unifamiliares privados no entorno da Praça foi demolida para a construção de torres residenciais. Chalés, casas pré-modernas e 

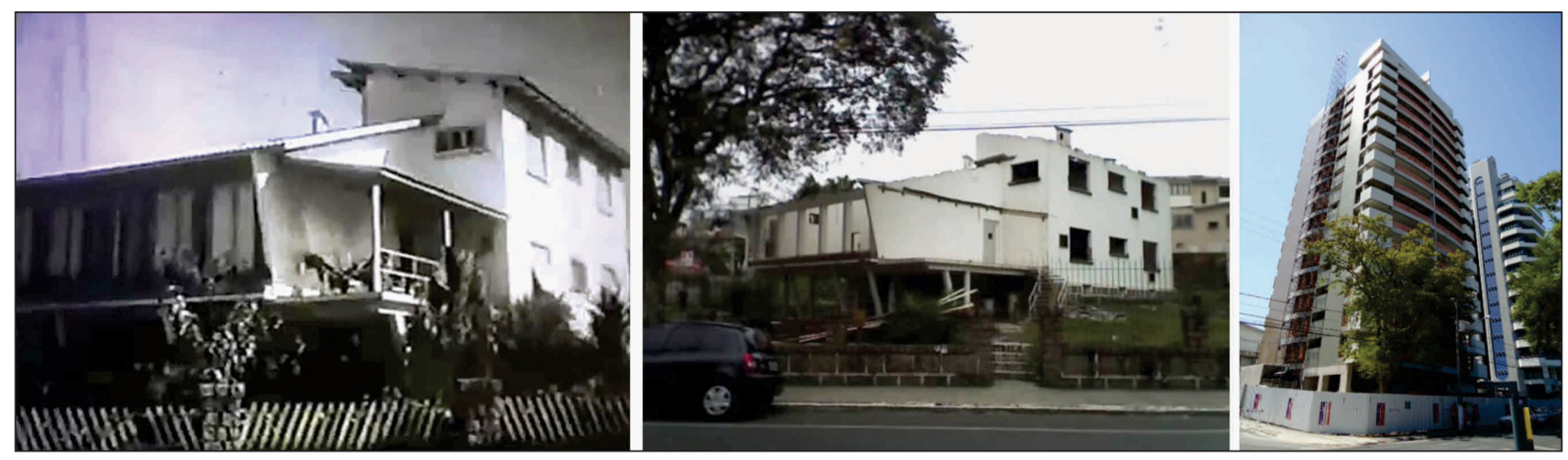

Figura 4 - A casa modernista, sua demoliç̃̃o em 2008 e o novo edifício residencial Fonte: Gericke (1960) [captura de tela], Manique (2008) e Construtora Fontana (2014a).

exemplares importantes da arquitetura doméstica modernista foram, aos poucos, sumindo da paisagem. Já citada neste texto, vale a pena destacar a residência de pilares em "V" construída nos anos 1940 numa das esquinas da Praça (Figura 4). Foi demolida em 2008, após negociação com uma construtora local. Situação semelhante aconteceu com o imóvel limítrofe, também datado do início do século XX, mas ainda sem o arrojo da arquitetura moderna. Foi substituído pelo Residencial Lodge, edifício de alto padrão de 16 pavimentos. No lado oposto da Praça, nas proximidades da esquina da rua Engo Fiúza da Rocha com a rua Santo Antônio, outros residenciais substituíram casas térreas e, somados aos edifícios construídos desde as décadas de 1980 e 90, configuraram um conjunto tipológico verticalizado.

Com o mercado imobiliário aquecido, se já eram precárias quaisquer intenções para a preservação da arquitetura, o olhar sobre a paisagem se demonstrou completamente inexistente. Casos de demolição de imóveis com potencial valor histórico são até hoje comuns nas ruas adjacentes à Praça e foram sacrificando, gradativamente, visuais onde a paisagem em escala humana, compatível com o conjunto histórico, ainda sobrevivia ao processo de renovação. Exemplo de maior notoriedade foi a construção do Residencial Porto Brindise, uma torre de 18 pavimentos localizada logo atrás do alinhamento das antigas casas térreas do DNPM (Figura 5). Sua agressão através da altura incompatível é representativa da urbanização contemporânea em Criciúma, que rompeu com a possibilidade de buscar conciliar o adensamento e as necessidades econômicas da cidade com a valorização de seus acervos históricos. Complementa-se, para

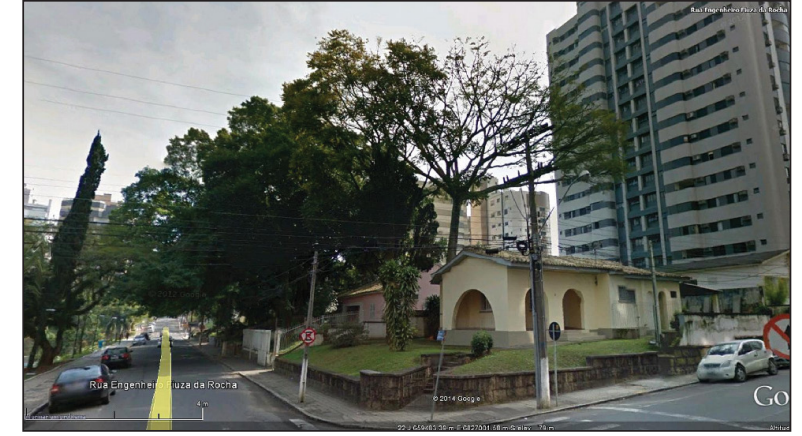

Figura 5 - À direita, a escala do Edifício Porto Brindise incompatível com 0 acervo histórico

Fonte: Google Street View (2013).

esta questão, que a relação entre densidade e altura não é diretamente proporcional.

Além das transformações tipológicas, é importante registrar as intenções de intervenção sobre o paisagismo original da Praça do Congresso. Nos últimos anos, ao menos duas situações tiveram grande repercussão na imprensa da cidade e deixaram evidente a necessidade do tombamento do espaço público. Na primeira, a construção em 2011 de um quiosque com mais de $140 \mathrm{~m}^{2}$ no meio da praça, o que dividiu a população, mas acabou sendo concretizado ${ }^{4}$; e na segunda, a intenção da Autarquia de Segurança, Trânsito e Transporte de Criciúma (ASTC) em 2013 de cercar o logradouro e controlar seu acesso sob justificativa da

\footnotetext{
4 Agravando ainda mais sua condição de instrumento fragmentador, são completamente questionáveis os critérios adotados no projeto arquitetônico do quiosque diante de sua localização na praça. Não se justifica que uma edificação rodeada por uma área de lazer consolidada configure fachadas de "fundos", com trechos em parede cega apenas com acessos de serviço.
} 
falta de segurança pública no período noturno. Esta última obra só não foi executada porque a população, especialmente a parcela mais jovem, foi contrária e se mobilizou ativamente para defender a permanência do espaço público livre.

Diante do quadro de constantes fragmentações, reconhece-se que o Plano Diretor atual, aprovado (após 7 anos de discussões) no dia 28 de dezembro de 2012 (justamente quando a cidade estava vazia) sob as diretrizes do Estatuto da Cidade (Lei 10.257/2001) (Criciúma, 2012), trouxe algumas novidades para o espaço da Praça do Congresso. A principal delas foi a demarcação de um zoneamento especial abrangendo a praça, as casas do DNPM na rua Engo Fiúza da Rocha e, de mesmo modo, os lotes com testada para a rua Barão do Rio Branco. Trata-se de uma Zona Especial de Interesse Histórico e Cultural (ZEIHC), que segundo a própria lei, está “[...] destinada à proteção e preservação do patrimônio ambiental cultural, abrangendo edificações ou conjuntos de edificações de valor arquitetônico e histórico [...]" (Criciúma, 2012, p. 49). Certamente um avanço para a proteção do espaço público e dos imóveis patrimoniais mais relevantes, mas que ainda não os protege de modo permanente. Na verdade, se analisadas as possibilidades do Plano, deduz-se que os imóveis continuam passíveis às mais diversas possibilidades de intervenção, o que é demonstrado pelas seguintes observações:

1. A ZEIHC é uma forma de proteção moderada, pois possíveis intervenções nos imóveis podem ser autorizadas pelo Conselho de Desenvolvimento Municipal (CDM) mediante parecer técnico da Prefeitura. Sob a mesma lógica, o zoneamento pode ser alterado, o que já tem sido feito em outros pontos da cidade, visto que ao CDM é atribuído o poder de "[...] deliberar sobre a criação, extinção ou modificação de normas oriundas do Poder Público que versem sobre planejamento físico-territorial [...]" (Criciúma, 2012, p. 26).

2. Os planos diretores no Brasil são revisados, em média, a cada dez anos, o que torna temporária a proteção atribuída pela ZEIHC.

3. Intervenções questionáveis associadas a discursos bem feitos, a exemplo do quiosque construído no meio da Praça do Congresso, são passíveis de aprovação na ZEIHC. Vale lembrar que naquele caso a iniciativa de descaracterização do espaço público partiu da própria Prefeitura.
4. Imóveis privados da década de 1960 abrangidos pela ZEIHC têm sido indevidamente descaracterizados para fins comerciais e podem continuar a sofrer intervenções caso o CDM interprete a não necessidade de sua preservação pelo fato de não comporem o acervo arquitetônico do DNPM.

Diante dessas e de outras especulações possíveis, pode-se dizer que o zoneamento especial sobre a Praça do Congresso deixa margem para surpresas posteriores. Trata-se de um posicionamento legislativo ambíguo, o que torna iminente a necessidade do tombamento de todo o conjunto urbano. Além disso, chama atenção o fato de que nas ruas Lauro Müller e Santo Antônio o Plano continua a permitir construções de 16 pavimentos, o que demonstra que a visão de patrimônio associado à paisagem permanece sendo completamente negligenciada na produção da cidade. Os lotes nessas ruas não estão inseridos na ZEIHC, ainda que haja remanescentes importantes da arquitetura da primeira metade do século XX. É o caso do chalé localizado numa das esquinas da praça, no cruzamento das ruas Engo Fiúza da Rocha e Lauro Müller. Foi construído provavelmente na década de 1940 (mas tem possibilidade de ser datado dos anos 1930) e atualmente permanece sem amparo de tombamento. Já na esquina da Lauro Müller com a Barão do Rio Branco, a Residência Balsini (1965) e seu vizinho, um chalé dos anos 1940, foram postos abaixo nos primeiros meses de 2014 para a construção de dois condomínios residenciais, ambos licenciados sob a legislação atual. Ironicamente, para os lotes defronte à Praça localizados na rua Santo Antônio, onde já se consolidou um conjunto edificado completo de aproximadamente 10 pavimentos, o Plano atual diminuiu o gabarito para 4 (Figura 6).

Pimenta (2013, p. 95) considera que "[...] o Plano Diretor possui a virtualidade da construção do espaço social, mas pode se transformar em seu contrário, dependendo da maneira como as medidas são postas e combinadas". Deveria se tratar de um instrumento de Estado, com viés democrático, para a regulamentação do mercado e o reconhecimento de direitos sociais. Não é o caso do Plano Diretor de Criciúma e das legislações que o precederam. 0 posicionamento político da Câmara de Vereadores, ao distorcer o 


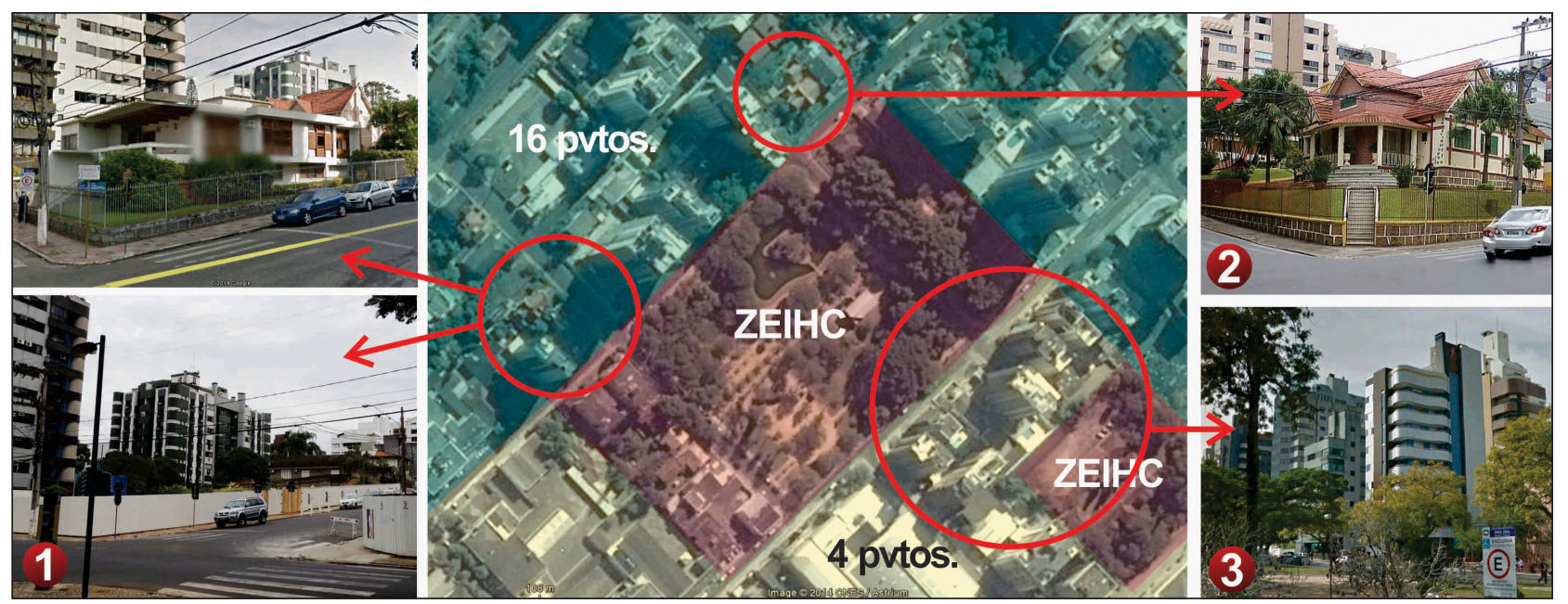

Figura 6 - Zoneamento do Plano Diretor de 2012 (Criciúma, 2012)

Fonte: Elaborado pelo autor com base em Google Maps (2014) e Google Street View (2011b).

Nota: (1) Demolição da Residência Balsini e de um chalé / (2) Chalé na esquina da Praça do Congresso à mercê da especulação imobiliária / (3) Ocupaç̦ão em zoneamento de 4 pavimentos.

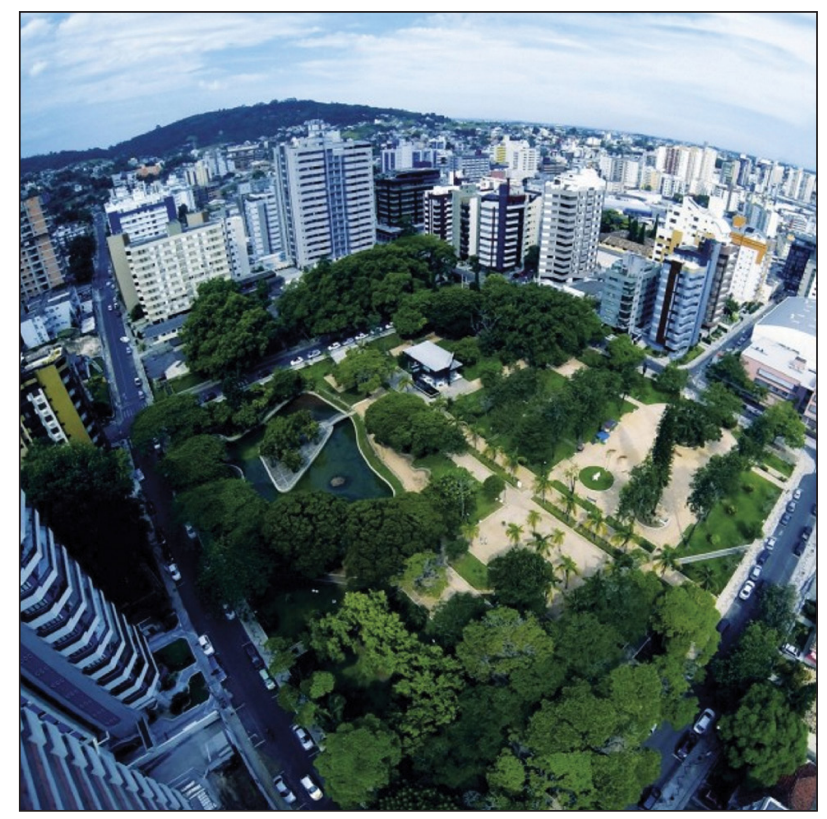

Figura 7 - Praça do Congresso em 2014

Fonte: Construtora Fontana (2014b).

texto original discutido pela comunidade através da aprovação de emendas requeridas por proprietários de imóveis e representantes do Sinduscon ${ }^{5}$, deixa evidente o desinteresse pela construção de uma proposta urbana socialmente coerente para um ambiente historicamente estabelecido.

\footnotetext{
5 Sinduscon - Sindicato da Indústria da Construção Civil do Sul Catarinense.
}

A demora para um posicionamento e a falta de clareza em relação aos reais interesses do setor público para o conjunto da Praça do Congresso vão contribuindo para o seu rápido desaparecimento da paisagem central (Figura 7). Uma perda irreparável, dada sua importância como vínculo identitário com o período carbonífero e com a cidade moderna que um dia se almejou construir. Fica claro, por enquanto, que o modelo que vai tomando formas ao invadir a paisagem materializa negligências sistêmicas à memória urbana e à história, que deveriam ser consideradas aspectos fundamentais do direito à cidade.

\section{Algumas considerações}

As fragmentações mais recentes no entorno da Praça do Congresso e em outras áreas do centro de Criciúma advertem que, ao serem conduzidas pelo capital imobiliário, as cidades brasileiras têm caminhado a um modelo de urbanização que as tem tornado cada vez mais iguais umas as outras. Arrisca-se até mesmo dizer que, na continuidade das dinâmicas atuais, só restarão no Brasil os monumentos históricos mais importantes, geralmente vinculados a atrações turísticas, a centros urbanos tombados ou que acarretariam em prejuízos eleitorais caso fossem substituídos ou descaracterizados. 
Trata-se, evidentemente, de um quadro nefasto de amesquinhamento da produção urbana, especialmente porque reduz a cidade a um instrumento de amortização de crises econômicas, que foi o caso de Criciúma nos anos 1990, e que, num estágio mais avançado, tem "[...] desempenhando um papel fundamental no reinvestimento dos lucros, a uma escala geográfica crescente, mas ao preço de criar fortes processos de destruição criativa que espoliaram as massas de qualquer direito à cidade [...]" (Harvey, 2013).

Diante da iminente crise urbana, torna-se fundamental a propagação de resistências. Em $O$ Direito à Cidade, Lefebvre (2001, p. 113) aborda que "[...] apenas grupos, classes ou frações de classes sociais capazes de iniciativas revolucionárias podem se encarregar das, e levar até a sua plena realização, soluções para os problemas urbanos [...]". Acompanhando as dinâmicas sociais mais contemporâneas, Criciúma tem ensaiado resistências. Se não fosse o posicionamento contrário da população, possivelmente o cercamento à Praça do Congresso teria sido implantado e levado para outros espaços públicos. De modo semelhante, apesar do decepcionante resultado, foi representativa a atuação de setores da sociedade para a elaboração de um plano diretor que assegurasse valores sociais e que estivesse adequado às infraestruturas disponíveis na cidade.

De maneira inédita, as dinâmicas atuais têm feito das paisagens históricas uma pauta representativa da conquista da cidade como espaço e direito de todos.

\section{Referências}

Balthazar, L. F. (2001). Criciúma - Memória e vida urbana [Dissertação de mestrado]. Programa de Pós-Graduação em Geografia, Centro de Filosofia e Ciências Humanas, Universidade Federal de Santa Catarina, Florianópolis.

Braverman, H. (1977). Trabalho e capital monopolista: a degradação do trabalho no século XX. Rio de Janeiro: Zahar Editores.

Buchalla, A. P., \& Verano, R. (1999). A nova Valadares: há mais de 20.000 catarinenses da região de Criciúma vivendo nos Estados Unidos. São Paulo: Veja. Recuperado em 26 de julho de 2014, de http://veja.abril.com.br/061099/p_128.html Calvino, I. (1990). As cidades invisíveis. São Paulo: Companhia das Letras.
Carneiro, F. J. C. (2012). Narrativas de minha memória. Criciúma: EdiUNESC.

Construtora Fontana. (2014a). Recuperado em 10 de outubro de 2014, de http://www.construtorafontana.com. br/arquivos/obras/gra_dsc05522-20140606093131.jpg

Construtora Fontana. (2014b). Recuperado em 15 de outubro de 2014, de http://www.construtorafontana.com. br/arquivos/ilustracoes/gra_vista-20140502154349.jpg

Costa, M. O. (2010). A cidade como texto: tecendo saberes e conhecendo Criciúma. São Paulo: Baraúna.

Criciúma. Prefeitura Municipal (1973, 11 de abril). Lei № 947, de 11 de abril de 1973. Plano Diretor de Criciúma. Criciúma: Prefeitura Municipal.

Criciúma. Prefeitura Municipal (1984, 12 de dezembro). Lei № 2.039, de 29 de novembro de 1984. Dispõe sobre o Zoneamento de Uso do Solo e dá outras providências. Criciúma: Prefeitura Municipal.

Criciúma. Prefeitura Municipal (2012, 28 de dezembro). Lei Complementar № 095, de 28 de dezembro de 2012. Institui o Plano Diretor Participativo do Município - PDPM de Criciúma, e dá outras providências. Criciúma: Prefeitura Municipal.

Gericke, W. (1960). Criciúma: eixo econômico do Sul Catarinense [Arquivo de vídeo]. Recuperado em 10 de outubro de 2014, de https://www.youtube.com/watch?v=VNU-nPwdMIM

Google. (2011a). Google Street View. Recuperado em 03 de outubro de 2014, de https://www.google.com.br/ maps/@-28.675091,-49.369439,3a,75y,184.44h,98.12t/ data $=! 3 \mathrm{~m} 4 ! 1 \mathrm{e} 1 ! 3 \mathrm{~m} 2$ !1sC0c5hXycwiH2hyzYemrM_Q!2e0

Google. (2011b). Google Street View Recuperado em 05 de outubro de 2014, de https://www.google.com.br/ maps/@-28.675085,-49.369605,3a,75y,249.16h,85.19t/ data $=! 3 \mathrm{~m} 4 ! 1 \mathrm{e} 1 ! 3 \mathrm{~m} 2$ !1sjxxwh7vF_DS81BzOYdxFNA!2e0

Google. (2013). Google Street View Recuperado em 06 de outubro de 2014, de https://www.google.com.br/maps/@28.675117,-49.367549,3a,75y,355.07h,105.69t/data=!3m 4!1e1!3m2!1stV0xvY8MwhiHQINaL4Kh-w!2e0

Google. (2014). Google Maps Recuperado em 05 de outubro de 2014, de https://www.google.com.br/ maps/@-28.6751996,-49.3689245,294m/data=!3m1!1e3

Harvey, D. (2007). Condição pós-moderna (16a ed.). São Paulo: Loyola. 
Harvey, D. (2013). 0 direito à cidade. In Blog da Boitempo. Recuperado em 30 de setembro de 2014, de http:// blogdaboitempo.com.br/2013/11/22/o-direito-a-cidade

Lefebvre, H. (2001). $O$ direito à cidade (5a ed.). São Paulo: Centauro.

Manique, N. (2008). Praça do Congresso perde casarão dos Balsini. Criciúma: Portal Engeplus. Recuperado em 10 de outubro de 2014, de http://www.engeplus.com.br/noticia/ memoria/2008/praca-do-congresso-perde-casarao-dos-balsini/

Monteiro, R. A. (2013). As legislações de proteção ao patrimônio histórico e os tombamentos municipais em Criciúma/SC. In Anais do I Simpósio de Patrimônio Cultural de Santa Catarina - "Patrimônio Cultural: Saberes e Fazeres Partilhados" (p. 1-11). Florianópolis: ANPUH.

Nascimento, D. (2012). Faces da Urbe: processo identitário e transformações urbanas em Criciúma/SC (1945-1980). Criciúma: EdiUNESC.
Pimenta, M. C. A. (2013). O Plano Diretor e a construção do espaço social em Florianópolis (SC). In A. B. Peres, C. S. Tornquist, M. C. A. Pimenta, L. F. B. Peres, L. R. M. Silveira, \& V. L. N. Dias (Orgs.), Reconstruindo paisagens: desafios socioespaciais para a Grande Florianópolis (p. 95-119). Florianópolis: Editora da UFSC.

Santos, M. (2009). A urbanização brasileira (5a. ed.). São Paulo: EDUSP.

Skyscrapercity. (2011). Recuperado em 15 de setembro de 2014, de http://www.skyscrapercity.com/showthread. php?t=1302869\&page $=5$

Zappelini, O. (1970). Recuperado em 10 de outubro de 2014, de http://www.engeplus.com.br/cache/noticia/ memoria/2009/criciuma-anos-70/criciuma-anos-70-75520.jpg

Recebido: Ago. 08, 2014

Aprovado: Nov. 05, 2014 